Best Practice \& Research Clinical Gastroenterology: Surveillance in GI Practice, Guest

Edited by Michal F. Kamiński \& Michael Bretthauer

\title{
Surveillance of patients with inflammatory bowel disease
}

Jessica X. Yu ${ }^{1}$, James E. East ${ }^{2}$ and Tonya Kaltenbach ${ }^{3}$

1 Division of Gastroenterology and Hepatology, Stanford University Medical Center, Stanford, CA

2 Translational Gastroenterology Unit, John Radcliffe Hospital, University of Oxford, Oxford, UK

3 San Francisco Veterans Affairs Medical Center, University of California, San Francisco, CA

Corresponding Author:

Tonya Kaltenbach, MD MAS

Associate Professor of Clinical Medicine, University California San Francisco

San Francisco Veterans Affairs Medical Center

4150 Clement Street (VA111B), Bldg 203, 2A-67

San Francisco, CA 94121

Phone: $415-221-4810 \times 24103$

Email: endoresection@me.com 


\begin{abstract}
:
Patients with inflammatory bowel disease involving the colon are at increased risk for developing colorectal cancer. Colonoscopy surveillance is important to identify and treat IBD associated dysplasia. The SCENIC consensus provides evidence- based recommendations for optimal surveillance and management of dysplasia in IBD. Chromoendoscopy, with the surface application of dyes to enhance mucosal visualization, is the superior endoscopic surveillance strategy to detect dysplasia. Most dysplasia is visible, and can be endoscopically resected. Future studies should determine the effect of new surveillance strategies on the incidence of CRC and mortality in patients with IBD.
\end{abstract}

Word Count: 4,956

Key Words: Inflammatory bowel disease, chromoendoscopy, image-enhanced endoscopy, colorectal cancer, dysplasia, colonoscopy, surveillance, SCENIC

Abbreviations: UC, ulcerative colitis, IBD, inflammatory bowel disease; CRC, colorectal cancer; SCENIC, Surveillance for Colorectal Endoscopic Neoplasia Detection and Management in IBD Patients International Consensus Recommendations; 


\section{Introduction}

High quality surveillance in patients with ulcerative colitis (UC) or Crohn's disease involving the colon is an important clinical issue. Compared with the general population, inflammatory bowel disease (IBD) patients have a significantly higher risk for the development of colorectal cancer (CRC) and of interval $\operatorname{CRC}(1,2)$. Colorectal dysplasia is considered the precursor to CRC, and thus, colonoscopy is recommended to detect and remove dysplasia to prevent $\mathrm{CRC}$, or to detect CRC at an early, curable stage.

Many factors influence the quality and success of surveillance, involving both the physician and patient, and the equipment and tools. Endoscopists must recognize colorectal dysplasia, adequately sample mucosa, appropriately classify, differentiate and completely remove endoscopically resectable dysplasia, and recommend appropriate follow up intervals. Patients must medically maintain their disease and adhere to recommended follow up, including time intervals and bowel preparation instructions for staging and surveillance exams. Timely attendance for surveillance is a particular issue; with studies suggesting up to $50 \%$ of patients do not attend scheduled surveillance.(3) Equipment and tools, such as high definition systems and enhanced imaging tools, such as contrast dyes, influence the yield of dysplasia detection in surveillance.(4)

Advances in the understanding and approach to the detection and management of IBDassociated colorectal dysplasia over the past decade have paved a path towards improved surveillance strategies and practices. In this review, we will focus on the 
SCENIC (Surveillance for Colorectal Endoscopic Neoplasia Detection and Management in IBD Patients International Consensus Recommendations) consensus proposed evidence-based statements for the surveillance and management of dysplasia in $\operatorname{IBD}(4$, 5). We will present the approach to CRC surveillance in patients with IBD, including the chromoendoscopy technique with targeted biopsy. We will describe the endoscopic features of dysplasia in patients with IBD, apply the nomenclature for the assessment of endoscopic resectability, and highlight management strategies for identified dysplasia.

\section{Epidemiology}

CRC is the third most common cancer worldwide. Though a recent meta-analysis suggested the risk of colorectal cancer in IBD is decreasing(6), it is still higher relative to the general population(7). The decline has been attributed to better medical therapies to control inflammation such as anti-TNF biological therapies, more effective colonoscopic surveillance, and possible chemoprophylaxis effects of 5-aminosalicylates (5-ASAs) (7, 8).

Risk factors for CRC that are specific to IBD patients have been established from national population-based cohorts and registries, as well as from referral cohorts. These unique risk factors include extent, severity and duration of inflammation and previous history of dysplasia(1). Patients with long standing extensive colitis (diagnosis $>10$ years and $>50 \%$ involvement) have a 7 fold increased risk to develop CRC compared to IBD patients without long-standing extensive colitis, such as isolated ulcerative 
proctitis(9). Active inflammation, even on histology, has been found to be another independent risk factor(10); as are the endoscopic findings of foreshortened colons, strictures and inflammatory polyps(11).

A meta-analysis of 16,844 patients showed that there was a 4 fold increased risk for CRC in UC patients with primary sclerosing cholangitis compared to those without(12). Unlike their counterparts, patients with comorbid primary sclerosing cholangitis are at increased risk of CRC from the time of their diagnosis. They also tend to have a younger age of onset of IBD, are more likely to have total colitis and quiescent IBD manifestations, which have been suggested as reasons for the increased CRC risk(13).

CRC surveillance in IBD

CRC is believed to arise from dysplasia, and thus, surveillance colonoscopy is recommended to detect and remove dysplasia, and ultimately to prevent CRC. However, it is important to note that direct evidence that surveillance for neoplasia in IBD patients reduces colorectal cancer incidence and mortality is lacking.

The understanding of the natural history of dysplasia in colitis is limited. Not all patients carry the same risk for dysplasia and not all dysplasia carries the same risk for progression. Few guidelines though provide stratified surveillance strategies according to individual risk profile. Current US guidelines recommend surveillance every 1-2 years after 8-10 years duration of disease, with exception of yearly intervals in those 
with a family history of $\mathrm{CRC}$ in a $1^{\text {st }}$ degree relative or active inflammation. Those with risk factors such as primary sclerosing cholangitis should have yearly surveillance starting at the time of diagnosis.

The British Society of Gastroenterology (BSG) and the European Crohns and Colitis Organization (ECCO) also advocate initiating surveillance 8-10 years after diagnosis and offer additional guidance on surveillance intervals based on risk stratification. BSG and ECCO guidelines recommend yearly surveillance for patients with moderate to severe active inflammation, history of stricture, dysplasia, primary sclerosing cholangitis or family history of $\mathrm{CRC}$ in a first-degree relative aged $<50$ years old. Whereas, patients with only mildly active inflammation, history of post-inflammatory polyps or family history of CRC (if no affected family members $<50$ years old) need surveillance every 2-3 years; and patients with only left sided colitis or Crohn's colitis with $<50 \%$ colon involved need surveillance colonoscopy only every 5 years. Notably, the recommended interval for surveillance for patients with extensive colitis but no active endoscopic and histologic inflammation is also 5 years(14)(15).

Historical studies, during the fiberoptic endoscopy era, raised the concern that dysplasia was invisible at colonoscopy(16). As such, initial surveillance strategies utilized random 4-quadrant biopsies taken every $10 \mathrm{~cm}$. To improve sensitivities for detecting dysplasia, a minimum of 33 biopsies should be taken. Despite this, the random biopsy technique only samples $<0.1 \%$ of the mucosa, and more importantly, has a low yield for dysplasia(17), and similar to any surveillance method, no benefit in mortality(18). Van 
den Broek and colleagues, for example, detected only $9 \%$ of dysplasia using the random biopsy technique (19). Moreover, in a pooled analysis of 48,522 random biopsies from 1635 patients a mere 45 (0.09\%) showed dysplasia. $(4,5)$ Advances in endoscopic technology and technique have shown that IBD-associated dysplasia is visible during colonoscopy. Over a decade ago, using high-resolution endoscopes, Rutter and colleagues showed most dysplastic lesions are endoscopically visible(20). The utility of random biopsy is, thus, in question(21). Should our surveillance practice identify the many with targeted or the few with random biopsies? A systematic review of studies in the video-endoscopic era revealed that among IBD patients with dysplasia, the dysplasia is visible in approximately $80 \%$ of patients examined with standard-definition colonoscopy and in approximately $90 \%$ of patients examined with high-definition white-light colonoscopy or chromoendoscopy $(4,5)$

\section{SCENIC guidelines}

The recently developed SCENIC international consensus statement offers rigorous evidence based guidance on appropriate surveillance and management of dysplasia in $\operatorname{IBD}(4,5)$. Based on moderate quality of evidence, it concluded that chromoendoscopy is the preferred method for the detection of dysplasia in IBD.

SCENIC followed the prescribed processes for guideline development from the Institute of Medicine, including systematic reviews, full synthesis of evidence and deliberations by panelists, and incorporation of the GRADE methodology. The consensus panel 
consisted of 21 experts representing a wide spectrum of stakeholders representing IBD specialty, general gastroenterology, advanced endoscopy, nursing, surgery and patient groups. The reviewers evaluated over 5000 abstracts and through rigorous evaluation included 33 articles for qualitative analysis. Consensus guidelines were developed through several rounds of deliberation. The SCENIC consensus statements were reviewed and endorsed by the American Gastroenterology Association (AGA), American Society of Gastrointestinal Endoscopy (ASGE), British Society of Gastroenterology (BSG), European Society of Gastrointestinal Endoscopy (ESGE), Canadian Association of Gastroenterology (CAG), Asian Pacific Association of Gastroenterology (APAGE), Japanese Gastroenterological Endoscopy Society (JGES).

Nine major conclusions were made including recommendations for both the surveillance and management of dysplasia and are summarized in Table 1. The key summary recommendations from SCENIC for surveillance colonoscopy included 1) the use of high definition and the routine performance of chromoendoscopy for the detection of dysplasia, 2) the endoscopic removal of visible dysplasia, and 3) referral to an endoscopist with expertise in IBD surveillance using chromoendoscopy with highdefinition colonoscopy for patients with endoscopically invisible dysplasia (confirmed by a GI pathologist)(4, 5).

\section{Chromoendoscopy}


Chromoendoscopy uses dye (methylene blue or indigo carmine) to enhance visualization of dysplasia. Chromoendoscopy with targeted biopsies has been shown to be more sensitive than white light endoscopy with random biopsies in detecting dysplasia and neoplasia in patients with IBD. Data from randomized trials demonstrate increased efficacy in the detection of lesions with chromoendoscopy compared to whitelight. However, most studies have assessed its use with standard definition(22-24). In a meta-analysis of 6 trials, chromoendoscopy with targeted biopsies was significantly superior to standard definition white-light colonoscopy in the detection of patients with dysplasia (incremental yield $=6 \%[95 \% \mathrm{Cl} 2.8-9.2]$; relative increase $=1.8[95 \% \mathrm{Cl} 1.2-$ 2.6]). Additionally, chromoendoscopy detected significantly more patients with endoscopically visible dysplasia compared with SD white-light colonoscopy (incremental yield $=7 \%[95 \% \mathrm{Cl} 3.0-10.0] ;$ relative increase $=2.3[95 \% \mathrm{Cl} 1.4-3.7])(24)$. One prospective, study using high definition colonoscopy in 75 patients with IBD identified significantly more dysplasia with chromoendoscopy (21\%) vs white-light alone (9\%; P = .007)(25) Recently, an interim analysis of a randomized trial also showed significantly higher detection of dysplastic lesions with high definition plus chromoendoscopy compared to high-definition white-light colonoscopy alone: 0.26 vs. 0.12 lesions per patient(26). Despite adding an average of approximately 11 minutes to the procedure(24), chromoendoscopy has been found to be cost effective. (27)

Multiple European societies (BSG, ECCO), Asian societies (APAGE, JGES) and government agencies (National Institute for Clinical Excellence, NICE; United Kingdom) endorse the use of chromoendoscopy for the surveillance of CRC in IBD. The 2015 
ASGE guideline now suggests chromoendoscopy as the preferred method; where as random biopsies should only be used if chromoendoscopy is not technically feasible or not available.(21)

\section{Description of the Chromoendoscopy Technique}

In selecting patients to undergo chromoendoscopy, it is important that the patients' disease activity is in remission and that they have good quality bowel preparation. Dye can be applied by various methods including spray catheter, flushing pumps(28) and recently as controlled released oral formulation taken with bowel preparation(29). Most clinical studies used spray catheters, but Picco and colleagues showed similar efficacy with the pump technique(25). The pump technique, which is probably the simplest, lowest cost, and currently most time efficient, is illustrated in Figure 2 . The dilute dye solution ( $0.04 \%$ methylene blue or $0.03 \%$ indigo carmine) should be prepared to be compatible for use with the forward wash jet. Additionally, a $0.13 \%$ indigo carmine solution or $0.2 \%$ methylene blue solution should be prepared for use during lesion characterization(4, 5, 21, 30).

During insertion, it is important to thoroughly wash and suction the mucosa to remove any residual stool and debris, which may hinder lesion detection during dye spraying. Once the cecum is reached, the water container should be exchanged for the dilute dye container. Dye should be sprayed toward the non-dependent mucosal surface for efficiency. This should be performed segmentally during withdrawal. Excess dye is suctioned to leave a thin layer of dye over the entire examined mucosa. Careful 
inspection should then be performed with attention to areas that may be elevated, depressed, villous, and nodular in appearance or are friable or have an abnormal vascular pattern. Once a suspicious area has been identified, a 60cc syringe of concentrated dye should be used to spray the mucosa directly through the working channel to allow improved characterization of visible dysplasia and margins.

SCENIC recommended the use of the Paris classification (polypoid - pedunculated, sessile, non-polypoid - slightly elevated, flat, depressed) to classify macroscopic appearance of dysplasia, with the modifications to describe the presence of ulceration and the border of the lesion. The term Dysplasia Associated Lesion or Mass (DALM) and its derivations should no longer be used. $(4,5,21)$ When dysplasia is detected, it should be characterized as "endoscopically resectable" or "non-endoscopically resectable". The term "endoscopically resectable indicates that 1 ) distinct margins of the lesion could be identified, 2) the lesion appears to be completely removed on visual inspection after endoscopic resection, 3) histologic examination of the resected specimen is consistent with complete removal, and 4) biopsy specimens taken from mucosa immediately adjacent to the resection site are free of dysplasia on histologic examination". $(4,5)$

\section{Alternative techniques:}

The value of chromoendoscopy in the detection of dysplasia beyond high definition white light colonoscopy has been questioned. High definition endoscopy provides images of higher pixel density than standard definition. Based on a prospective trial that 
showed the significant benefit in dysplasia detection using chromoendoscopy (21\%) compared to high definition white light alone (9\%), $p=0.007$, the SCENIC guideline suggested the use of chromoendoscopy even when using high definition white light colonoscopy $(4,5)$. Since the SCENIC publication, several retrospective studies comparing high definition and chromoendoscopy have been published suggesting that chromoendoscopy is needed (Table 2)(31-33). One large trial of 401 patient conducted by Mooiweer and colleagues did not show a difference between the two techniques(34). However, the study era involved standard and high definition system use, the study design was non-randomized and retrospective, and the study endoscopists did not receive any specific training on the use of chromoendoscopy. More recently, a large multicenter Spanish study of expert and community practitioners showed superiority of CE with targeted biopsies to white-light endoscopy for dysplasia detection, with an incremental detection yield for CE of $68.5 \%$ (95\% CI 64.8\% to $72.2 \%)$. High definition colonoscopes were used in $58.5 \%$ of the cases. The CE-incremental detection yield for dysplasia was comparable between standard definition and high definition ( $51.5 \%$ vs $52.3 \%, p=0.30)$. Furthermore, an interim report of a randomized trial further supports the significant value of high definition chromoendoscopy in IBD surveillance colonoscopy to detect more dysplasia compared to high definition white light colonoscopy.(26)

\section{Narrow band imaging}

Narrow band imaging (NBI) is an endoscope based imaged enhancement technique. It has been studied for CRC screening in IBD but has not been shown to be superior to white light or chromoendoscopy $(5,35)(36,37)$. The results of the studies not document a benefit of chromoendoscopy over NBI. Future non-inferiority studies may be of interest. 


\section{Optimal Resection Technique}

The decision of endoscopic vs surgical management of dysplasia in colitis is based on endoscopic and histologic findings as well as patient rated factors such as age, comorbidities, patient preferences and other risk analysis.(4) (30, 38). In general, endoscopic resection is recommended for appropriate patients with endoscopically visible dysplastic lesions followed by surveillance colonoscopy 3-6 months, and then yearly thereafter. Colectomy is reserved for patients who have endoscopically unresectable lesions or endoscopically invisible high-grade dysplasia despite chromoendoscopy examinations or multifocal dysplasia. $(4,5,21)$

Endoscopic resection is recommended over colectomy for polypoid dysplasia, as the risk of future colorectal cancer is low in subsequent surveillance. A recent systematic review of 10 studies, which followed 376 patients with IBD with resected polypoid dysplasia for a mean of 54 months, reported an annualized incidence for CRC of $0.5 \%(39) .$. Endoscopic resection is also suggested for non-polypoid dysplasia, but data on subsequent colorectal cancer risk is not yet available(40). Though recent advances in endoscopic imaging have improved the recognition of nonpolypoid lesions in patients with IBD, their natural history and outcomes for complete endoscopic resection are less known. Simple polypectomy may not be adequate for complete resection of polypoid dysplasia. Deepak and coauthors report high rates of incomplete endoscopic resection that could contribute to recurrent dysplasia. Among patients with endoscopically treated dysplastic lesions at index colonoscopy, almost half of the 67 lesions had incomplete resection. Cold forceps or cold snare was predominantly used(41). These results 
emphasize the urgency to focus efforts on improving the endoscopic management of dysplastic lesions in colitis. If the lesion is assessed to be endoscopically resectable, then using the proper technique to ensure complete endoscopic removal is critical. Endoscopic mucosal resection (EMR) is the preferred method. Hybrid endoscopic mucosal resection and endoscopic submucosal dissection (ESD) are other potential techniques, often determined by the lesion characteristics as well as the endoscopist's skills and experience (Figure 2)(40, 42, 43).

Once resection is completed, biopsies of the adjacent area should be performed to document clearance. Additionally the area should be tattooed to help facilitate surveillance. A history of dysplastic lesions, particularly non-polypoid dysplastic lesions due to their flat shape and need for more advanced endoscopic resection techniques, is a risk factor for CRC. Therefore, it is prudent to consider more frequent surveillance for non-polypoid lesions with the initial surveillance colonoscopy in 3- 6 months. Similarly, large polypoid lesions $>15 \mathrm{~mm}$ requiring EMR or ESD for resection are recommended to have their initial surveillance in 3-6 months. For smaller polypoid lesions, post polypectomy surveillance is recommended in 1 year $(4,5)$.

Dysplasia identified by random biopsy should be confirmed with chromoendoscopy as approximately $30 \%$ of patients may be found to have a lesion which may be amenable to resection(41). If no visible lesion is identified, management with endoscopic surveillance versus surgery can be individualized. Patient with endscopically invisible low grade dysplasia may be managed with intensive surveillance as risk of developing 
cancer is relatively low $(14,95 \% \mathrm{Cl}$ : 5-34 per 1000 patient years), while patients with endscopically invisible high grade dysplasia should consider colectomy(44). For

younger (aged $<65$ years) patients without co-morbidity who have endoscopically invisible low or high grade dyplasia, colectomy may be a more clinically and cost effective strategy(45).

\section{Future Directions}

Prospective longitudinal studies of colonoscopy surveillance and CRC incidence and mortality would be of high value, and provide guidance on its effectiveness. Moreover, they could help us risk stratify patients to the most appropriate surveillance intervals. While we await such high level trials, and we continue to routinely perform surveillance, it is important to use the currently shown optimal method. Although numerous studies clearly support the use of chromoendoscopy for the surveillance of CRC in IBD patients, implementation of this technique into clinical practice remains a challenge. Potential barriers that have been identified include provider level factors such as training and systemic level factors such as reimbursement $(46,47)$. Future efforts should focus on the development of standardized procedure algorithms as well as training tools including video libraries, atlases and texts to improve learning curves and detection rates. Additionally, standardizing nomenclature and photo documentation will form the basis of developing quality metrics for the field. Prospective longitudinal studies will be needed to monitor the rate of interval cancers, need for surgery and mortality, and cost effectiveness with new surveillance programs. 


\section{Summary}

Patients with inflammatory bowel disease involving the colon are at increased risk for colorectal cancer and should undergo surveillance. It is clear that random biopsies alone are no longer clinically or cost effective for the identification of dysplasia. Multiple studies have demonstrated that chromoendoscopy increases the efficacy of IBD surveillance and is superior to high definition white light and other equipment based image-enhanced endoscopy techniques. Chromoendosocopy has been supported by multiple international society guidelines as well as the high-quality, SCENIC guidelines.

Additionally, SCENIC highlights the role of endoscopy in management of dysplastic lesions. Dysplastic lesions should be described by the Paris classification (polypoid pedunculated, sessile, non-polypoid - slightly elevated, flat, depressed) and should be characterized as endoscopically resectable or non-resectable. Endoscopic resection is recommended over colectomy for resectable lesions. Emphasis should be placed on using the appropriate technique to ensure complete resection of dysplastic tissue and adherence to close colonoscopic surveillance.

\section{Practice Points}

- Patients with IBD are at increased risk for developing CRC and should undergo surveillance.

- Chromoendoscopy should be used as the primary screening technique to identify dysplasia. 
- Once identified, dysplastic lesions should be described by the Paris classification (polypoid - pedunculated, sessile, non-polypoid - slightly elevated, flat, depressed) and should be characterized as endoscopically resectable or non-resectable. Endoscopic resection is recommended over colectomy for resectable lesions.

Research Agenda

- Prospective longitudinal studies on effect of surveillance and CRC incidence and mortality.

- Determining optimal chromoendoscopy surveillance technique.

\section{POLITICAL AGENDA}

Widespread adoption of chromoendoscopy is limited by lack of re-imbursement for time, effort and resources. This should be a priority issue for GI societies to optimize IBD cancer prevention.

Conflict of Interest:

Jessica Yu: none

Tonya Kaltenbach: Consultant, Olympus America

James East: Consultant, Olympus UK

No Funding Source for this article 
Figure 1. Preparation of dye for pan chromoendoscopy. A-B. A 10ml ampule of $1 \%$ methylene blue is drawn up and mixed with $240 \mathrm{ml}$ of sterile water. C-D. This solution can be exchanged for the water in the foot pump apparatus. E-F. Use of the foot pump allows efficient delivery of the dilute $0.04 \%$ methylene blue solution for lesion detection.
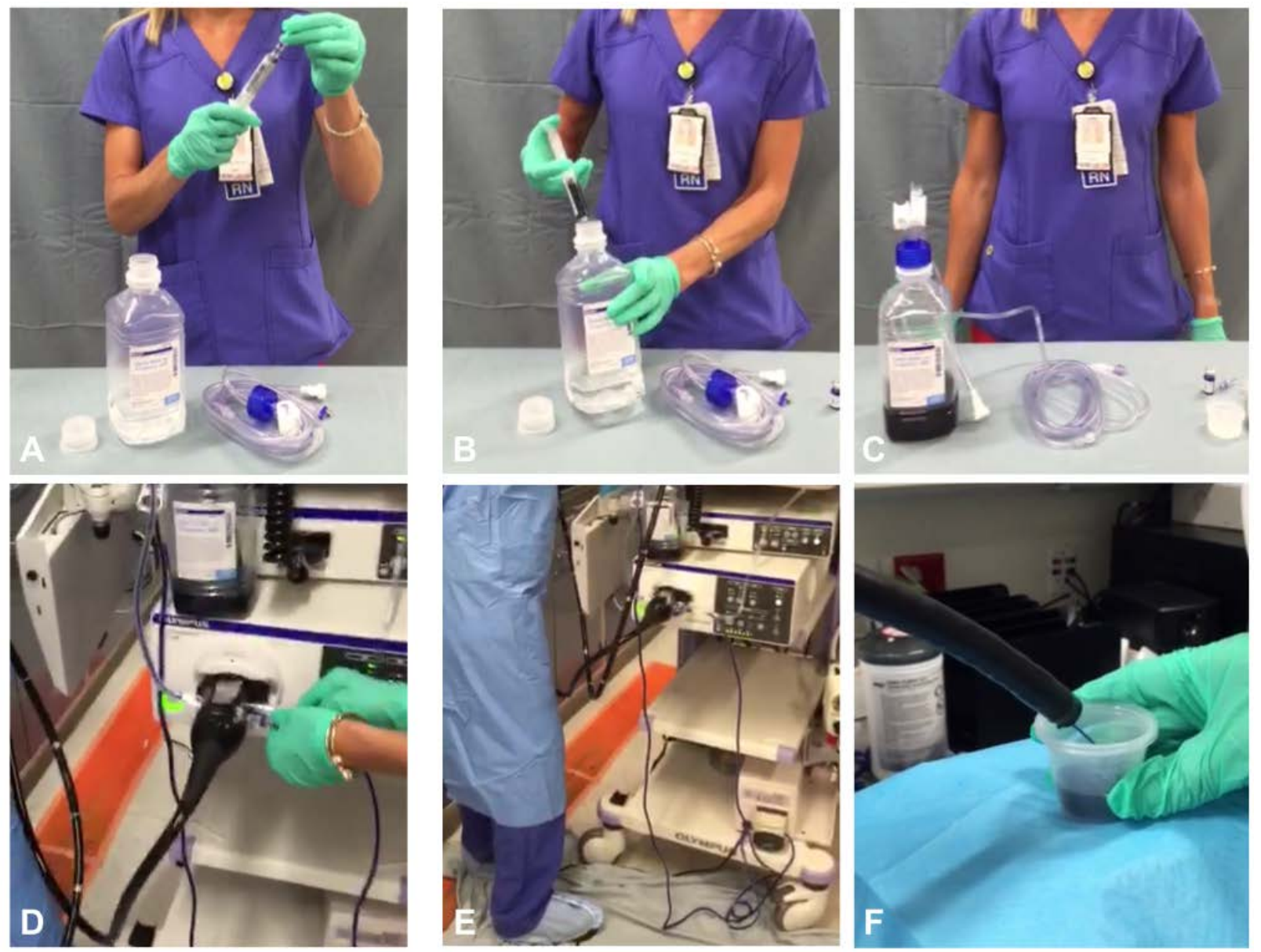
Figure 2. A. $2 \mathrm{~cm}$ sessile transverse colon polyp. B. The same lesion after indigo carmine chromoendoscopy, which improves visualization of the margins. C-D. En-Bloc inject and cut endoscopic mucosal resection performed. E. Final specimen, pathology resulted tubulovillous adenoma, low grade dysplasia. G. Repeat colonoscopy after 3 months shows no residual disease.
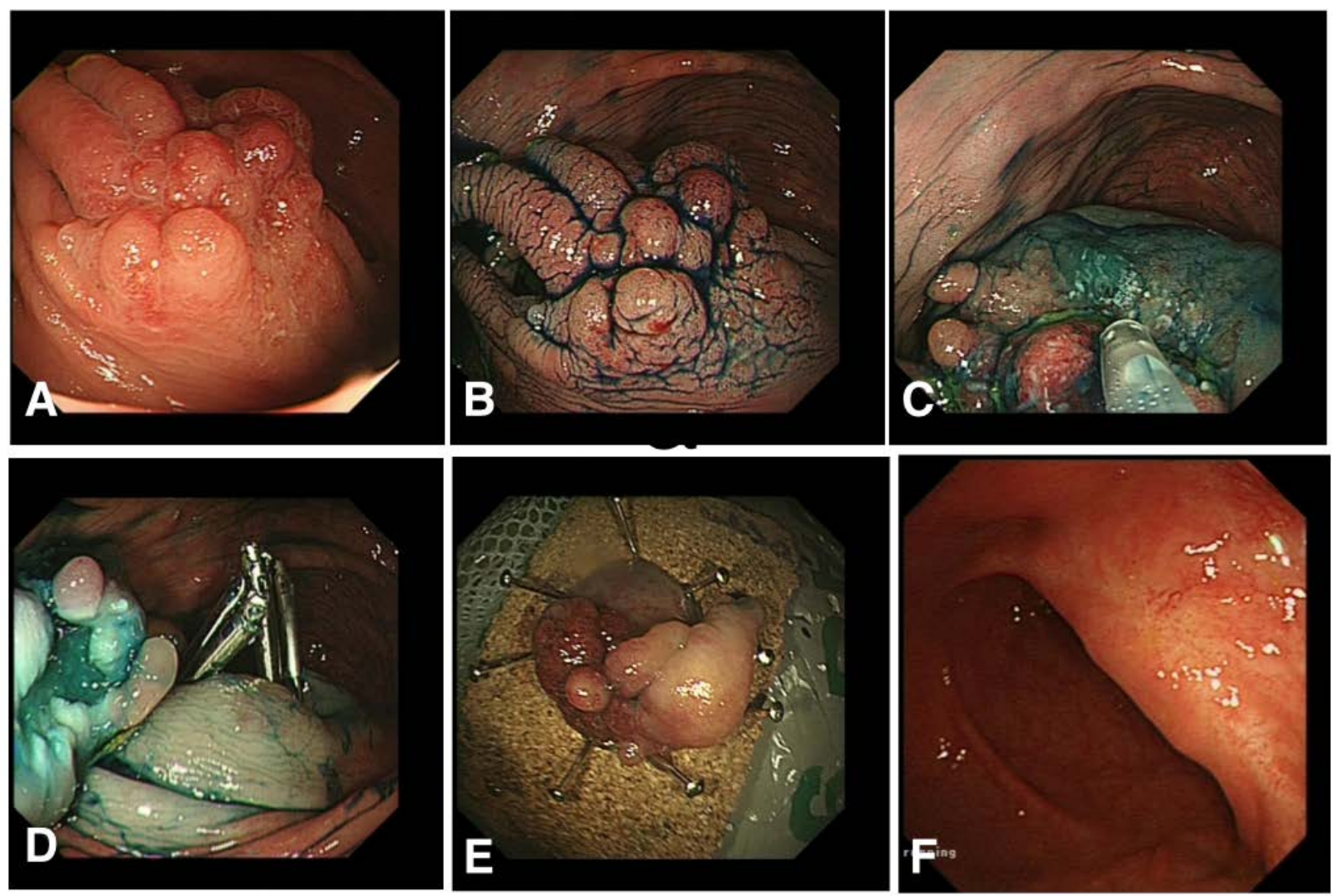
Table 1. SCENIC consensus statements; adapted from Laine et al. 2015(4, 5)

Dysplasia detection on surveillance colonoscopy

1. High definition white-light colonoscopy is recommended over standard definition white-light colonoscopy for surveillance (strong recommendation, low-quality evidence)

2. Chromoendoscopy is recommended over standard definition white-light colonoscopy during surveillance (strong recommendation, moderatequality evidence)

3. Chromoendoscopy is recommended over high-definition white-light colonoscopy (conditional recommendation, low-quality evidence)

4. Narrow-band imaging is not suggested in place of standard definition or high-definition white-light colonoscopy (conditional recommendation, moderate-quality evidence)

5. Narrow-band imaging is not suggested in place of chromoendoscopy for surveillance (conditional recommendation, moderate-quality evidence)

Management of dysplasia during colonoscopy

6. Surveillance colonoscopy recommended over colectomy after complete removal of endoscopically-resectable polypoid lesions (strong recommendation, very low-quality evidence)

7. Surveillance colonoscopy recommended over colectomy after complete removal of endoscopically-resectable non-polypoid lesions (strong recommendation, very low-quality evidence)

8. For patients with endoscopically-invisible dysplasia, referral to endoscopist with expertise in IBD surveillance using chromoendoscopy with highdefinition colonoscopy (conditional recommendation, very low-quality evidence) 
Table 2. Post-scenic Publications evaluating chromoendoscopy (CE) versus standard definition (SD) and high definition (HD) white light colonoscopy

\begin{tabular}{|c|c|c|c|c|c|c|}
\hline $\begin{array}{l}\text { Author, } \\
\text { Year }\end{array}$ & $\begin{array}{l}\text { Study } \\
\text { Period }\end{array}$ & $\begin{array}{l}\text { Study } \\
\text { Design }\end{array}$ & Scope & Cohort & $\begin{array}{l}\text { Dysplastic } \\
\text { lesions }\end{array}$ & Conclusion \\
\hline $\begin{array}{l}\text { Choi et } \\
\text { al(31) } \\
\text { UK 2015 }\end{array}$ & $\begin{array}{l}2002- \\
2012\end{array}$ & Retrospective & SD & Surveillance & 267 & CE superior \\
\hline $\begin{array}{l}\text { Marion et } \\
\text { al(32). US } \\
2016\end{array}$ & $\begin{array}{l}2005- \\
2011\end{array}$ & Retrospective & SD & Surveillance & 44 & CE superior \\
\hline $\begin{array}{l}\text { Gasia et } \\
\text { al.(33) } \\
\text { Canada, } \\
2016\end{array}$ & $\begin{array}{l}2011- \\
2014\end{array}$ & Retrospective & $\mathrm{SD} / \mathrm{HD}$ & Surveillance & 243 & $\begin{array}{l}\text { CE no } \\
\text { difference } \\
\text { from HD, } \\
\text { superior to } \\
\text { SD }\end{array}$ \\
\hline $\begin{array}{l}\text { Mooiwer } \\
\text { et al. (34) } \\
\text { Dutch, } \\
2015\end{array}$ & $\begin{array}{l}2000- \\
2013\end{array}$ & Retrospective & $\mathrm{SD} / \mathrm{HD}$ & Surveillance & 401 & $\begin{array}{l}\text { CE no } \\
\text { difference }\end{array}$ \\
\hline $\begin{array}{l}\text { Deepak et } \\
\text { al(41) US } \\
2016\end{array}$ & $\begin{array}{l}2006- \\
2013\end{array}$ & Retrospective & $\mathrm{HD}$ & Dysplasia & 95 & CE superior \\
\hline $\begin{array}{l}\text { Mohamme } \\
\text { d et al(26). } \\
\text { UK } 2016\end{array}$ & $\begin{array}{l}2012- \\
2015\end{array}$ & RCT & $\mathrm{HD}$ & Surveillance & 20 & CE superior \\
\hline
\end{tabular}




\section{References}

1. Beaugerie L, Itzkowitz SH. Cancers Complicating Inflammatory Bowel Disease. N Engl J Med. 2015;373(2):195.

2. Wang YR, Cangemi JR, Loftus EV, Jr., Picco MF. Rate of early/missed colorectal cancers after colonoscopy in older patients with or without inflammatory bowel disease in the United States. Am J Gastroenterol. 2013;108(3):444-9.

3. Vienne A, Simon T, Cosnes J, Baudry C, Bouhnik Y, Soule JC, et al. Low prevalence of colonoscopic surveillance of inflammatory bowel disease patients with longstanding extensive colitis: a clinical practice survey nested in the CESAME cohort. Aliment Pharmacol Ther. 2011;34(2):188-95.

4. Laine L, Kaltenbach T, Barkun A, McQuaid KR, Subramanian V, Soetikno R, et al. SCENIC international consensus statement on surveillance and management of dysplasia in inflammatory bowel disease. Gastroenterology. 2015;148(3):639-51 e28.

5. Laine L, Kaltenbach T, Barkun A, McQuaid KR, Subramanian V, Soetikno R, et al. SCENIC international consensus statement on surveillance and management of dysplasia in inflammatory bowel disease. Gastrointest Endosc. 2015;81(3):489-501 e26.

6. Lutgens MW, van Oijen MG, van der Heijden GJ, Vleggaar FP, Siersema PD, Oldenburg B. Declining risk of colorectal cancer in inflammatory bowel disease: an updated meta-analysis of population-based cohort studies. Inflamm Bowel Dis. 2013;19(4):789-99.

7. Herrinton LJ, Liu L, Levin TR, Allison JE, Lewis JD, Velayos F. Incidence and mortality of colorectal adenocarcinoma in persons with inflammatory bowel disease from 1998 to 2010. Gastroenterology. 2012;143(2):382-9.

8. Kappelman MD, Farkas DK, Long MD, Erichsen R, Sandler RS, Sorensen HT, et al. Risk of cancer in patients with inflammatory bowel diseases: a nationwide populationbased cohort study with 30 years of follow-up evaluation. Clin Gastroenterol Hepatol. 2014;12(2):265-73 e1.

9. Beaugerie L, Svrcek M, Seksik P, Bouvier AM, Simon T, Allez M, et al. Risk of colorectal high-grade dysplasia and cancer in a prospective observational cohort of patients with inflammatory bowel disease. Gastroenterology. 2013;145(1):166-75 e8. 10. Gupta RB, Harpaz N, Itzkowitz S, Hossain S, Matula S, Kornbluth A, et al. Histologic inflammation is a risk factor for progression to colorectal neoplasia in ulcerative colitis: a cohort study. Gastroenterology. 2007;133(4):1099-105; quiz 340-1.

11. Rutter M, Saunders B, Wilkinson K, Rumbles S, Schofield G, Kamm M, et al. Severity of inflammation is a risk factor for colorectal neoplasia in ulcerative colitis.

Gastroenterology. 2004;126(2):451-9.

12. Soetikno RM, Lin OS, Heidenreich PA, Young HS, Blackstone MO. Increased risk of colorectal neoplasia in patients with primary sclerosing cholangitis and ulcerative colitis: a meta-analysis. Gastrointest Endosc. 2002;56(1):48-54.

13. Boberg KM, Lind GE. Primary sclerosing cholangitis and malignancy. Best Pract Res Clin Gastroenterol. 2011;25(6):753-64.

14. Cairns SR, Scholefield JH, Steele RJ, Dunlop MG, Thomas HJ, Evans GD, et al. Guidelines for colorectal cancer screening and surveillance in moderate and high risk groups (update from 2002). Gut. 2010;59(5):666-89. 
15. Annese V, Daperno M, Rutter MD, Amiot A, Bossuyt P, East J, et al. European evidence based consensus for endoscopy in inflammatory bowel disease. J Crohns Colitis. 2013;7(12):982-1018.

16. Tytgat GN, Dhir V, Gopinath N. Endoscopic appearance of dysplasia and cancer in inflammatory bowel disease. Eur J Cancer. 1995;31A(7-8):1174-7.

17. East JE. Colonoscopic Cancer Surveillance in Inflammatory Bowel Disease: What's New Beyond Random Biopsy? Clin Endosc. 2012;45(3):274-7.

18. Collins PD, Mpofu C, Watson AJ, Rhodes JM. Strategies for detecting colon cancer and/or dysplasia in patients with inflammatory bowel disease. Cochrane Database Syst Rev. 2006(2):CD000279.

19. van den Broek FJ, Stokkers PC, Reitsma JB, Boltjes RP, Ponsioen CY, Fockens P, et al. Random biopsies taken during colonoscopic surveillance of patients with longstanding ulcerative colitis: low yield and absence of clinical consequences. Am J Gastroenterol. 2014;109(5):715-22.

20. Rutter MD, Saunders BP, Wilkinson KH, Kamm MA, Williams CB, Forbes A. Most dysplasia in ulcerative colitis is visible at colonoscopy. Gastrointestinal Endoscopy. 2004;60(3):334-9.

21. American Society for Gastrointestinal Endoscopy Standards of Practice C, Shergill AK, Lightdale JR, Bruining DH, Acosta RD, Chandrasekhara V, et al. The role of endoscopy in inflammatory bowel disease. Gastrointest Endosc. 2015;81(5):1101-21 e1-13.

22. Marion JF, Waye JD, Present DH, Israel Y, Bodian C, Harpaz N, et al.

Chromoendoscopy-targeted biopsies are superior to standard colonoscopic surveillance for detecting dysplasia in inflammatory bowel disease patients: a prospective endoscopic trial. Am J Gastroenterol. 2008;103(9):2342-9.

23. Matsumoto T, Nakamura S, Jo Y, Yao T, Iida M. Chromoscopy might improve diagnostic accuracy in cancer surveillance for ulcerative colitis. Am J Gastroenterol. 2003;98(8):1827-33.

24. Soetikno R, Subramanian V, Kaltenbach T, Rouse RV, Sanduleanu S, Suzuki N, et al. The detection of nonpolypoid (flat and depressed) colorectal neoplasms in patients with inflammatory bowel disease. Gastroenterology. 2013;144(7):1349-52, 52 e1-6.

25. Picco MF, Pasha S, Leighton JA, Bruining D, Loftus EV, Jr., Thomas CS, et al. Procedure time and the determination of polypoid abnormalities with experience: implementation of a chromoendoscopy program for surveillance colonoscopy for ulcerative colitis. Inflamm Bowel Dis. 2013;19(9):1913-20.

26. Mohammed N, Kant P, Abid F, Rotimi O, Prasad P, Hamlin JP, et al. 446 High Definition White Light Endoscopy (Hdwle) Versus High Definition With Chromoendoscopy (Hdce) in the Detection of Dysplasia in Long Standing Ulcerative Colitis: a Randomized Controlled Trial. Gastrointestinal Endoscopy.81(5):AB148.

27. Elsadani NN, East JE, Walters JR. New 2010 British Society of Gastroenterology colitis surveillance guidelines: costs and surveillance intervals. Gut. 2011;60(2):282-3. 28. Tsiamoulos ZP, Saunders BP. Easy dye application at surveillance colonoscopy: modified use of a washing pump. Gut. 2011;60(5):740.

29. Repici A, Di Stefano AF, Radicioni MM, Jas V, Moro L, Danese S. Methylene blue MMX tablets for chromoendoscopy. Safety tolerability and bioavailability in healthy volunteers. Contemp Clin Trials. 2012;33(2):260-7. 
30. Kaltenbach T, Leite G, Soetikno R. Colonoscopy Surveillance and Management of Dysplasia in Inflammatory Bowel Disease. Curr Treat Options Gastroenterol. 2016;14(1):103-14.

31. Choi CH, Rutter MD, Askari A, Lee GH, Warusavitarne J, Moorghen M, et al. FortyYear Analysis of Colonoscopic Surveillance Program for Neoplasia in Ulcerative Colitis: An Updated Overview. Am J Gastroenterol. 2015;110(7):1022-34.

32. Marion JF, Waye JD, Israel Y, Present DH, Suprun M, Bodian C, et al.

Chromoendoscopy Is More Effective Than Standard Colonoscopy in Detecting Dysplasia During Long-term Surveillance of Patients With Colitis. Clin Gastroenterol Hepatol. 2016;14(5):713-9.

33. Gasia MF, Ghosh S, Panaccione R, Ferraz JG, Kaplan GG, Leung Y, et al. Targeted Biopsies Identify Larger Proportions of Patients With Colonic Neoplasia Undergoing HighDefinition Colonoscopy, Dye Chromoendoscopy, or Electronic Virtual Chromoendoscopy. Clin Gastroenterol Hepatol. 2016;14(5):704-12 e4.

34. Mooiweer E, van der Meulen-de Jong AE, Ponsioen CY, Fidder HH, Siersema PD, Dekker E, et al. Chromoendoscopy for Surveillance in Inflammatory Bowel Disease Does Not Increase Neoplasia Detection Compared With Conventional Colonoscopy With Random Biopsies: Results From a Large Retrospective Study. The American journal of gastroenterology. 2015;110(7):1014-21.

35. van den Broek FJ, Fockens P, van Eeden S, Stokkers PC, Ponsioen CY, Reitsma JB, et al. Narrow-band imaging versus high-definition endoscopy for the diagnosis of neoplasia in ulcerative colitis. Endoscopy. 2011;43(2):108-15.

36. Efthymiou M, Allen PB, Taylor AC, Desmond PV, Jayasakera C, De Cruz P, et al. Chromoendoscopy versus narrow band imaging for colonic surveillance in inflammatory bowel disease. Inflamm Bowel Dis. 2013;19(10):2132-8.

37. Ignjatovic A, East JE, Subramanian V, Suzuki N, Guenther T, Palmer N, et al. Narrow band imaging for detection of dysplasia in colitis: a randomized controlled trial. Am J Gastroenterol. 2012;107(6):885-90.

38. East JF, F. Soetikno, R. . Endoscopic Approach to Resection of Polypoid and Nonpolypoid Dysplasia in IBD. In: Kazorek RC, M. Wallce, M., editor. Endoscopy in Inflammatory Bowel Disease. Switzerland: Springer; 2015.

39. Wanders LK, Dekker E, Pullens B, Bassett P, Travis SP, East JE. Cancer risk after resection of polypoid dysplasia in patients with longstanding ulcerative colitis: a metaanalysis. Clin Gastroenterol Hepatol. 2014;12(5):756-64.

40. East JE, Toyonaga T, Suzuki N. Endoscopic management of nonpolypoid colorectal lesions in colonic IBD. Gastrointest Endosc Clin N Am. 2014;24(3):435-45.

41. Deepak P, Hanson GJ, Fletcher JG, Tremaine WJ, Pardi DS, Kisiel JB, et al. Incremental diagnostic yield of chromoendoscopy and outcomes in inflammatory bowel disease patients with a history of colorectal dysplasia on white-light endoscopy. Gastrointest Endosc. 2016;83(5):1005-12.

42. Iacopini F, Saito Y, Yamada M, Grossi C, Rigato P, Costamagna G, et al. Curative endoscopic submucosal dissection of large nonpolypoid superficial neoplasms in ulcerative colitis (with videos). Gastrointest Endosc. 2015;82(4):734-8.

43. Toyonaga T, Man IM, Morita Y, Sanuki T, Yoshida M, Kutsumi H, et al. The new resources of treatment for early stage colorectal tumors: EMR with small incision and simplified endoscopic submucosal dissection. Dig Endosc. 2009;21 Suppl 1:S31-7. 
44. Thomas T, Abrams KA, Robinson RJ, Mayberry JF. Meta-analysis: cancer risk of lowgrade dysplasia in chronic ulcerative colitis. Aliment Pharmacol Ther. 2007;25(6):657-68.

45. Parker BB, J. Wordsworth, S. East J. Keshav, S. George B. OC-014 Management of lowgrade dysplasia in ulcerative colitis in the uk national health service: the cost-effectiveness of immediate surgery versus ongoing surveillance. Gut. 2015;64(Suppl 1):A7-A8.

46. Sanduleanu S, Kaltenbach T, Barkun A, McCabe RP, Velayos F, Picco MF, et al. A roadmap to the implementation of chromoendoscopy in inflammatory bowel disease colonoscopy surveillance practice. Gastrointest Endosc. 2016;83(1):213-22.

47. Soetikno R, Kaltenbach T, McQuaid KR, Subramanian V, Kumar R, Barkun AN, et al. Paradigm Shift in the Surveillance and Management of Dysplasia in Inflammatory Bowel Disease (West). Dig Endosc. 2016;28(3):266-73. 